\title{
A Comparison of Stresses in Armor Joints With and Without Interlayers* ${ }^{*} \mathrm{CE}(\mathrm{CO}$

\author{
Richard E. Nygren \\ Sandia National Laboratories MS1129 \\ P. O. Box 5800, Albuquerque, NM 87185-5800
}

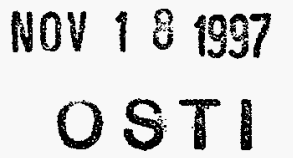

Abstract -- Post-fabrication and operating stresses in heat sinks with a $1 \mathrm{~mm}$ compliant layer (or no interlayer) between tungsten armor and a CuCrZr channel were analyzed with a $2-D$ finite element model with temperature dependent properties, generalized plane strain, and strain hardening.

\section{INTRODUCTION}

Reliable joining of armor to heat sinks for plasma facing components has been a persistent problem in fusion and a concern for the International Thermonuclear Experimental Reactor (TTER). Thin layers between the armor and heat sink have been used as diffusion barriers and to improve adherence; thick interlayers have been used for reducing stress. This paper summarizes some results on tungsten (W) armor from a broader study done for the ITER Project that included 1 or $2 \mathrm{~mm}$ interlayers, or none, between $\mathrm{W}$ or beryllium armor and CuCrZr or Hycon-3 heat sink.

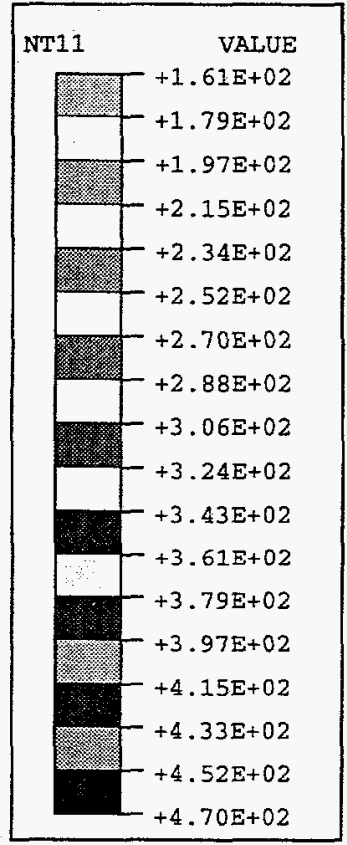

E1WCu5T550gps

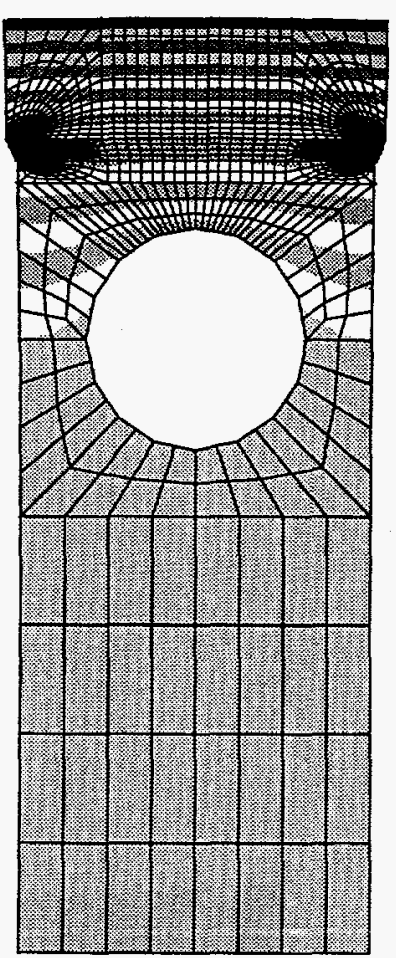

Fig 1. Temperature distribution for E1WCu with $5 \mathrm{MW} / \mathrm{m}^{2}$, $\mathrm{Y}$ axis is vertical and $\mathrm{X}$ axis is horizontal
The mesh was created in PATRAN; calculations were performed with ABAQUS. Results from the following three cases are presented in this paper.

EOW: $\quad 0 \mathrm{~mm}$ (no) interlayer

E150INT: $1 \mathrm{~mm}$ interlayer of W50-Cu50

E1WCu: $1 \mathrm{~mm}$ interlayer of $\mathrm{OFHC} \mathrm{Cu}$

Generalized 4 noded plane strain elements and temperature dependent properties were used for all parts of the model. Strain hardening of the $\mathrm{W}$ armor, interlayer materials (soft copper and Cu50-W50) and channel was included. Cu50-W50 is a hypothetical material with property values midway between those of $\mathrm{W}$ and $\mathrm{Cu}$. In the thermal cycling analysis, the simple kinematic hardening model in ABAQUS was used. Heat transfer to the coolant was calculated using a table of heat transfer coefficients obtained with the Eupiter code.

The thermal history begins with fabrication (stress free state) at $550^{\circ} \mathrm{C}$ followed by cooling to $25^{\circ} \mathrm{C}$. Then, the armor (top) surface receives a heat flux of $5 \mathrm{MW} / \mathrm{m}^{2}$ while the channel is cooled with $160^{\circ} \mathrm{C}$ water at $3.8 \mathrm{MPa}$ and $10 \mathrm{~m} / \mathrm{s}$. Fig. 1 shows the configuration and temperature distribution for the case with a $1 \mathrm{~mm} \mathrm{Cu}$ interlayer. The maximum surface temperature is about $470^{\circ} \mathrm{C}$, or is $456^{\circ} \mathrm{C}$ without an interlayer. Other analyses showed that fabrication at $900^{\circ} \mathrm{C}$ caused large residual stresses. These results, and debonding problems encountered in fabrication, led US researchers to lower the fabrication temperature (HIP at $-550^{\circ} \mathrm{C}$ ) and use thin $\mathrm{Cu}$ coatings on armor, substrate and interlayers.

\section{STRESSES}

In subsequent figures, the $X$ (lateral or $S 11$ ) and $Z$ (axial or s33) stresses or the $X$ and $X$ (vertical or S22) stresses and plastic strains are plotted versus position in the $\mathrm{X}$ direction along the armor joint. The "edge" (centroid of last element) is $0.022 \mathrm{~mm}$ from the true edge of the joint. The "center" element is $8 \mathrm{~mm}$ from the edge and abutts the centerline.

Figure 2 (next page) shows the residual stresses in the armor after fabrication and cool down. The $X$ stresses for the W50-Cu50 interlayer and for no interlayer are similar with $-390 \mathrm{Mpa}$ at the center of sample. Both the $\mathrm{Y}$ stresses (not shown) and $Z$ stresses are continuous with those in the interlayer, so the $\mathrm{Y}$ stresses in the armor along the joint are nearly the same as those shown in Fig. 3. The $Y$ stresses have relatively high compression at the edge. The $Z$ stress for the W50-Cu50 interlayer is high in the center.

"Sandia is a multiprogram laboratory operated by Sandia Corp., a Lockheed Martin Co., for the U. S. Dept. of Energy under Contract DE-AC04-94AL85000.

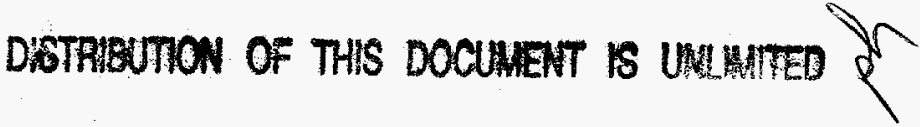
MASTER 


\section{DISCLAIMER}

This report was prepared as an account of work sponsored by an agency of the United States Government. Neither the United States Government nor any agency thereof, nor any of their employees, makes any warranty, express or implied, or assumes any legal liability or responsibility for the accuracy, completeness, or usefulness of any information, apparatus, product, or process disclosed, or represents that its use would not infringe privately owned rights. Reference herein to any specific commercial product, process, or service by trade name, trademark, manufacturer, or otherwise does not necessarily constitute or imply its endorsement, recommendation, or favoring by the United States Government or any agency thereof. The views and opinions of authors expressed herein do not necessarily state or reflect those of the United States Government or any agency thereof. 


\section{DISCLAmMER}

Portions of this document may be illegible in electronic image products. Images are produced from the best available original docomentert 


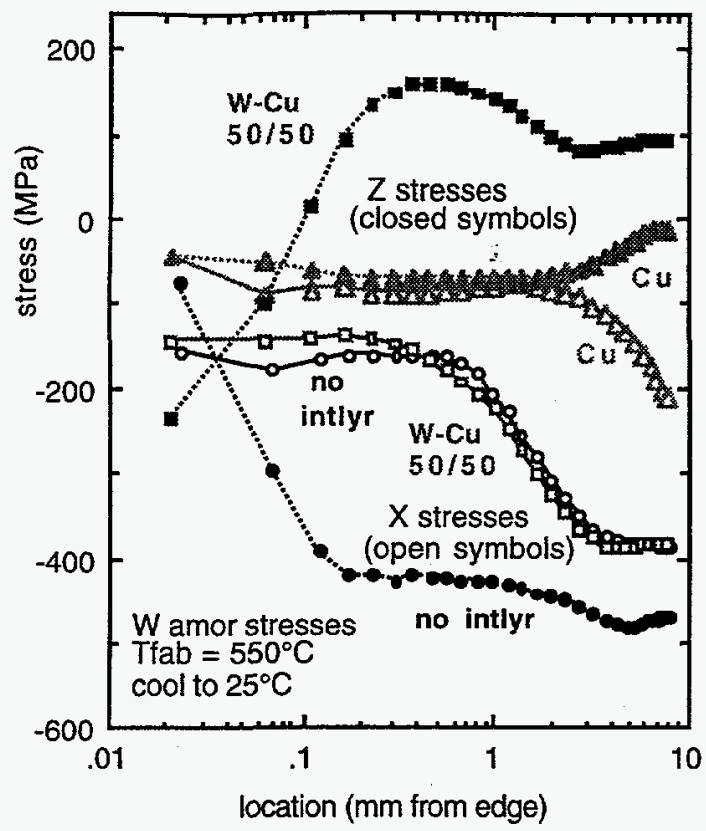

Fig 2 Residual stress in armor vs. position along joint

The residual stresses with the $1 \mathrm{~mm} \mathrm{Cu}$ interlayer are considerably less than those without the interlayer of with the W50-Cu50 interlayer; the axial residual stress in particular is greatly reduced. The stresses when the samples are heated (Fig. 4) are discussed later, but the figures are shown on this page so that comparisons with the post-fabrication stress state are easier.

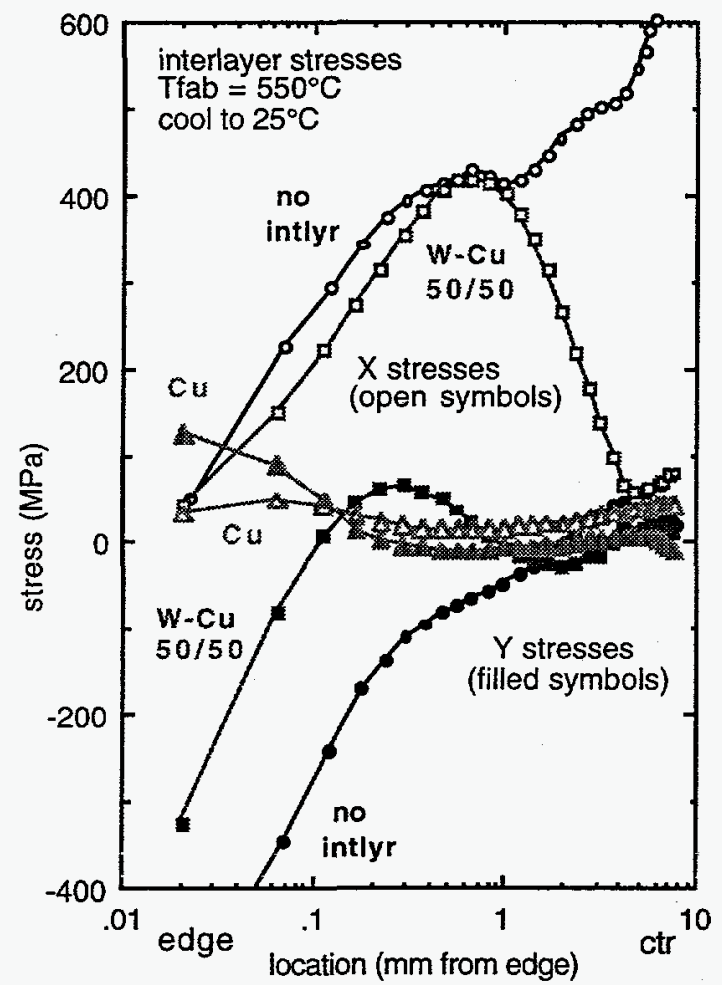

Fig 3 Residual stress in interlayer vs. position along joint

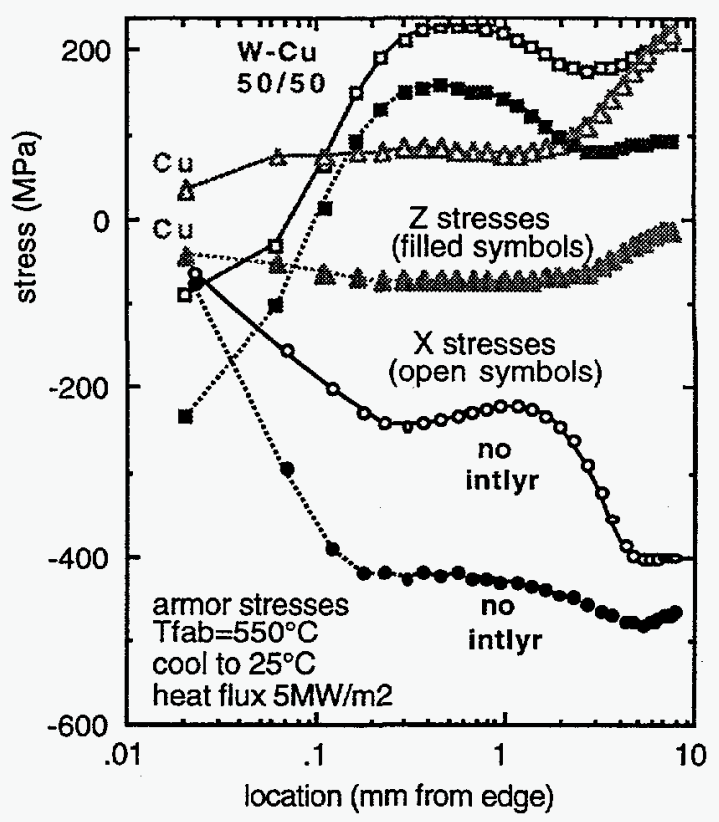

Fig. 4 Stress in armor vs. position along joint for $5 \mathrm{mw} / \mathrm{m}^{2}$

Fig. 3 shows residual stresses in the interlayer and Fig. 5 shows the stresses when the $5 \mathrm{MW} / \mathrm{m}^{2}$ heat load is applied. As expected, stresses in the $\mathrm{Cu}$ interlayer in the post-fabrication state (Fig. 3) are lower than those for either the channel (no interlayer) or the W50-Cu50 interlayer. For no interlayer, the $X$ and $Y$ stresses are fairly high near the center of the sample, and the $\mathrm{X}$ stress exceeds $600 \mathrm{MPa}$. Although the $\mathrm{X}$ stress for the W50-Cu50 in the interlayer near the centerline of the sample is relatively low, the $\mathrm{X}$ stress in the upper web of the channel below the W50-Cu50 interlayer is still high ( $>500$ $\mathrm{MPa}$, discussed later).

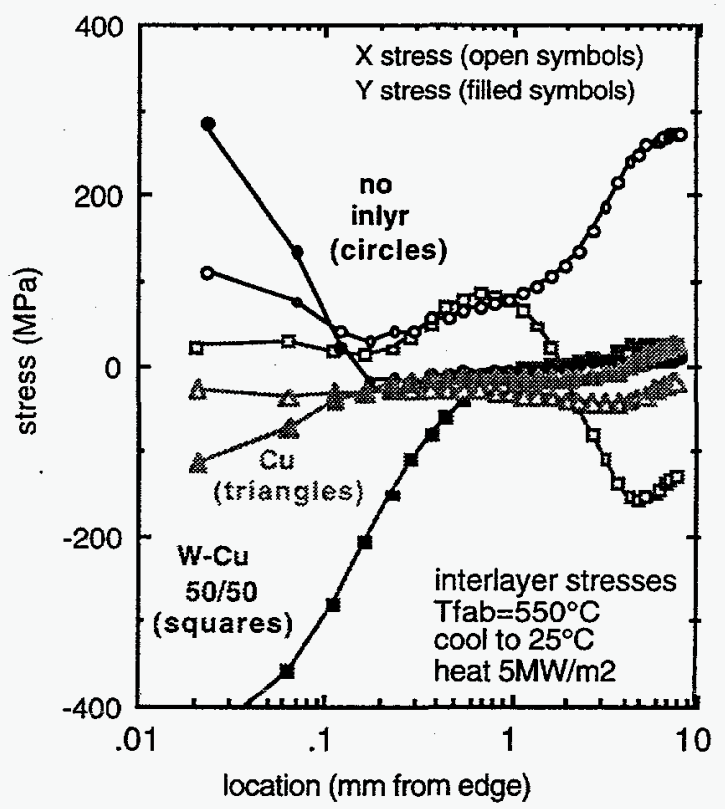

Fig 5 Stress in interlayer vs. position along joint for $5 \mathrm{mw} / \mathrm{m}^{2}$ 
When the $5 \mathrm{MW} / \mathrm{m}^{2}$ heat load is applied, the $\mathrm{X}$ stresses in the armor in the cases of the W50-Cu50 interlayer and the $\mathrm{Cu}$ interlayer become positive and $200 \mathrm{MPa}$ in the center, while for no interlayer, the armor is still in compression (X stress) with only a minor change in value. The $\mathrm{Y}$ stress (armor and interlayer are continuous) for the case of; no interlayer changes near the edge from $-600 \mathrm{MPa}$ (post-fabrication) to $\sim 300 \mathrm{MPa}$ (heated). The $\mathrm{Z}$ stresses change little from their postfabrication values.

In the W50-Cu50 interlayer and in the channel (case of no interlayer), the $\mathrm{X}$ stresses are significantly less with the heat load (Fig. 5) than in the post-fabrication state (Fig. 3) The X stresses are low in each case in the $\mathrm{Cu}$ interlayer.

The variations in how these stress profiles change from the post-fabrication state to the heated state arises in part because the cases differ in how the channel distorts. Fig 6 shows the displaced (strained) meshes for the cases of no interlayer and the $\mathrm{Cu}$ interlayer (heated cases.) The displacements are highly exaggerated $(50 \mathrm{X})$ so that the distortions are readily apparent. In the case of the $\mathrm{Cu}$ interlayer, the tensile stress along the inner sides of the channel web is about $50 \%$ less than that for the case of no interlayer.

The "bowing" of the armor results from the traction along the bottom of the armor when the thermal contraction of the $\mathrm{CuCrZr}$ channel during cooling after fabrication greatly exceeds that of the W armor. This "bowing" is sufficient to produce tension at the top of the armor in the cases here (see Fig. 9), and causes a strong "clamping" (negative $Y$ stress) at the edge, except where this is mitigated by plastic strain as for the $\mathrm{Cu}$ interlayer.

Under the strong surface heat load, the top of the armor goes into compression; this may be sufficient, either due to accommodation by plastic strain, as in the $\mathrm{Cu}$ interlayer, or by elastic strain, as in case with the W50-Cu50 interlayer, to produce tension in the $\mathrm{X}$ direction at the bottom of the armor. It also increases the clamping.

One might expect a related "peeling stress" in the center of the sample, where bowing would pull the armor away from the channel. This is not seen here in part because the clamping stress is so localized at the edge whereas the peeling stress is broadly distributed, and also because distortion of the webs in the channel accommodates this bowing.

\section{PLASTIC STRAIN}

Fig. 7 (next page) shows plastic strains along the joint in the armor and interlayer after fabrication. The very low plastic strains in the W50-Cu50 interlayer is notable. The main effect is lateral shear strain near the edge, seen here as $\mathrm{X}$ and $\mathrm{Y}$ strains of opposite sign which approach zero quickly away from the edge. In the $\mathrm{Cu}$ interlayer, the $\mathrm{X}$ and $\mathrm{Y}$ plastic strains near the edge were -9 and $7 \%$ respectively, about one and a half the values obtained with no interlayer. While the lateral strain relieves the mismatch in thermal expansion in the $\mathrm{X}$ direction, there is no relief for the axial strain in the configuration modeled here (no armor castellation); and accommodation in the $\mathrm{Y}$ direction of about $-2 \%$ occurs for the $1 \mathrm{~mm} \mathrm{Cu}$ interlayer and for no interlayer and about $-0.5 \%$ for the W50-Cu50 interlayer. Z strains are respectively $-0.70 \%$, $-0.65 \%$ and $-0.66 \%$ for no interlayer, $\mathrm{W} 50-\mathrm{Cu} 50$ and $\mathrm{Cu}$, and are uniform along the joint.

The results show some effect from work hardening. Plastic strains of $>20 \%$ near the edge were found in earlier cases with perfectly plastic materials as compared with (absolute) values less than $9 \%$ here. The calculated stresses indicate the degree to which the stresses are mitigated by an interlayer;

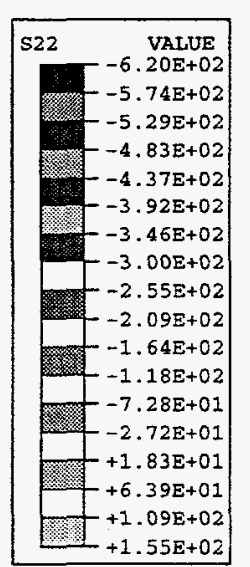

E0W5T550gpsHeat

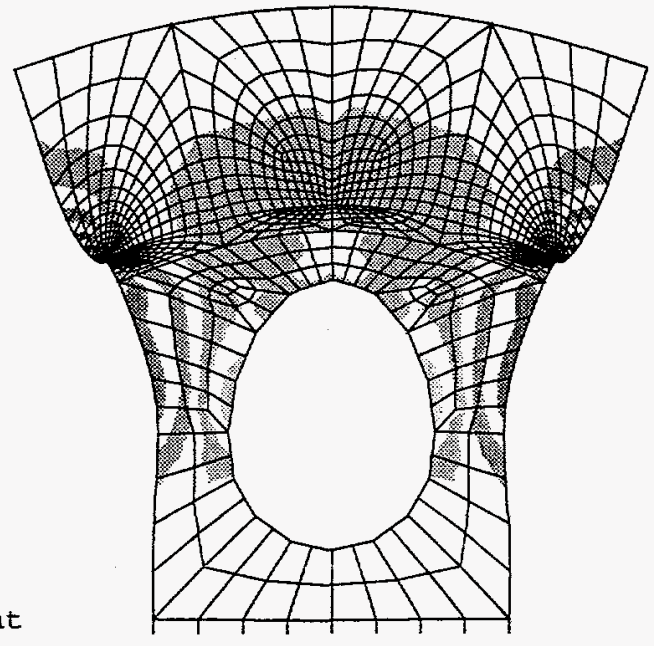

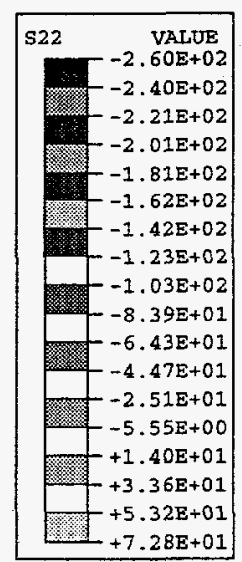

E1WCu5T550gpsHeat

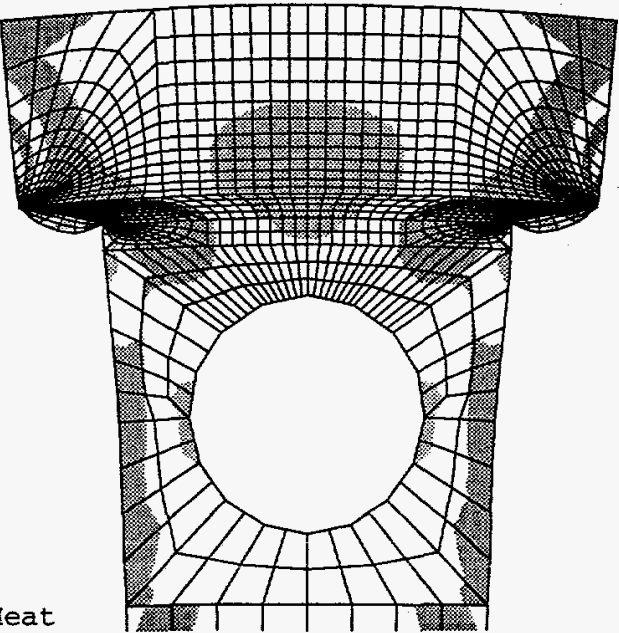

Fig. 6 Maps of $\mathrm{Y}$ stress for no interlayer (left) and the $\mathrm{Cu}$ interlayer (right). Deformation of mesh is magnified by $50 \mathrm{X}$. 


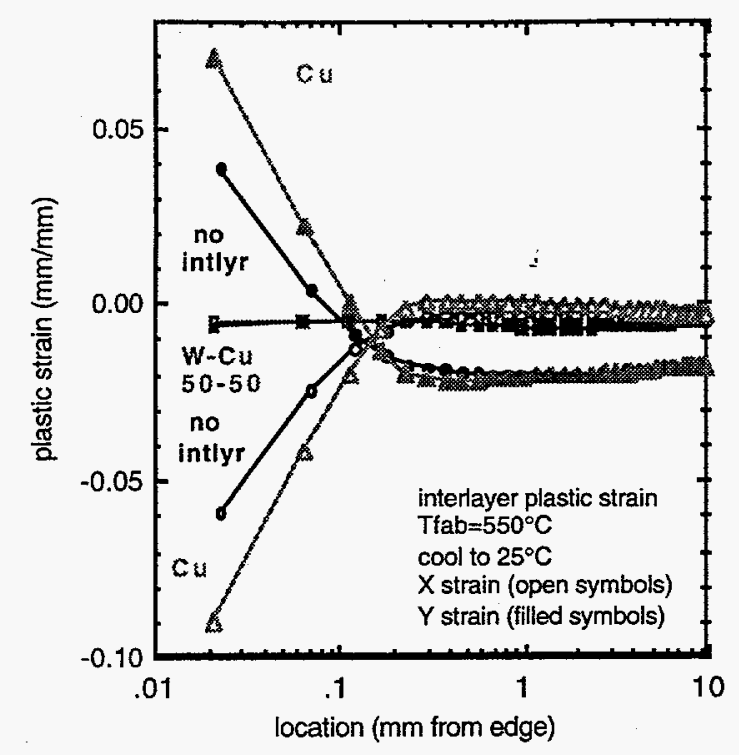

Fig 7 Plastic strain in interlayer vs. position along joint.

however, the value of stress at the joint's edge must be evaluated with reservation due to the well known stress singularity problem. (Where the joint meets the free surface, the equations cannot be satisfied no matter how fine the mesh; the results depends on mesh size.)

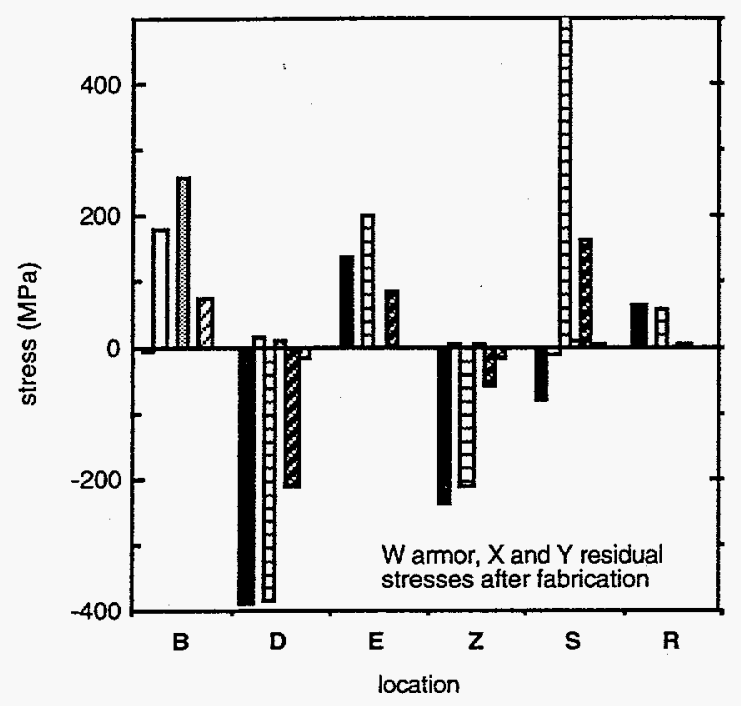

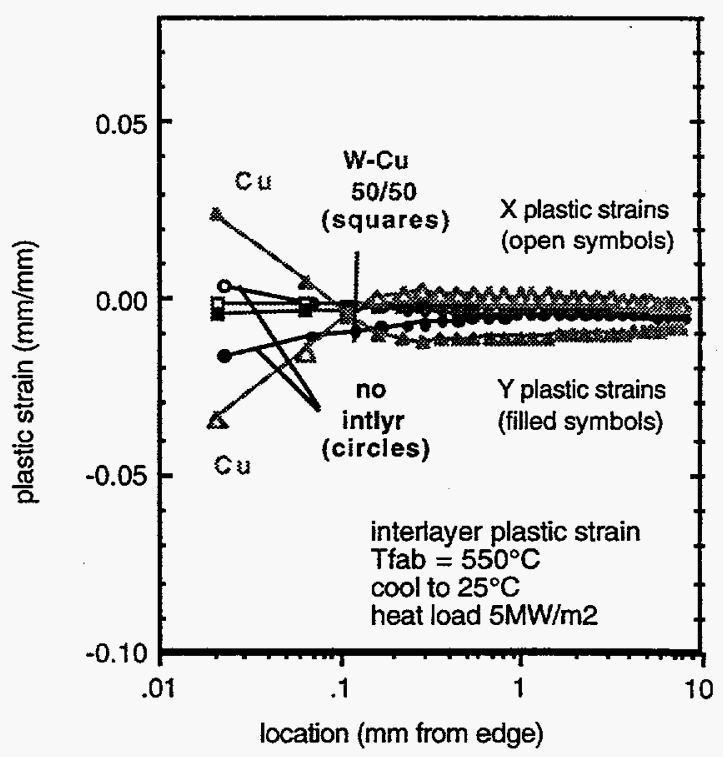

Fig 8 Plastic strain below the armor joint vs. position

Fig. 8 shows plastic strains in the interlayer along the joint for a heat load of $5 \mathrm{WM} / \mathrm{m}^{2}$. The strains in the W50-Cu50 interlayer are low, as before; and all strains are lower than after fabrication. Only for no interlayer are the strains at the edge reversed in sign compared with the residual fabrication strains.

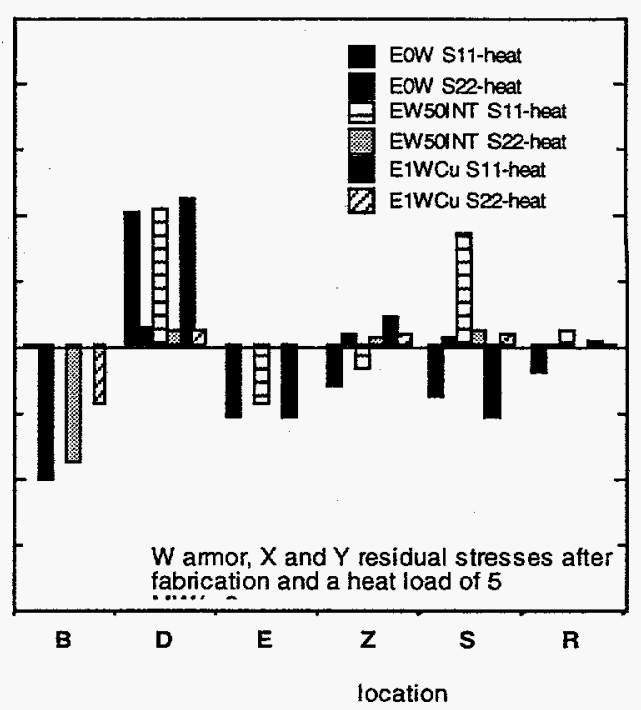

Fig. $9 \mathrm{X}(\mathrm{S} 11)$ and $\mathrm{Y}(\mathrm{S} 22)$ post-fabrication stresses (left) and stresses under heat load (right) at locations indicated in Fig. 7

\section{STRESSES AT OTHER LOCATIONS}

The stresses at several locations around the sample are shown in Figs. 9-10. (Fig. 6 shows the locations - B, D, Z, S, E, R.) As noted before, the $\mathrm{X}$ stresses at the top of the armor (E) change from positive to negative (left plot to right plot) while the $\mathrm{X}$ stresses at the base of the armor (D) do the reverse.

The von Mises stresses and pressures for the samples in the "as fabricated" state are shown in Fig. 10 (next page.) In all cases, the armor yields upon cooling from $550^{\circ} \mathrm{C}$; the plastic strain is about $-0.3 \%$ in the axial $(\mathrm{Z})$ direction; and the von Mises stress for the armor is nearly uniform at about 440 $\mathrm{MPa}$. (The higher value at location $\mathbf{R}$ is in the channel rather than the armor.) The dilatoric stress component, represented by the pressure, is positive (hydrostatic compression) in the armor and is the opposite (hydrostatic tension) in the channel, which shrunk more than the armor during cooling. 


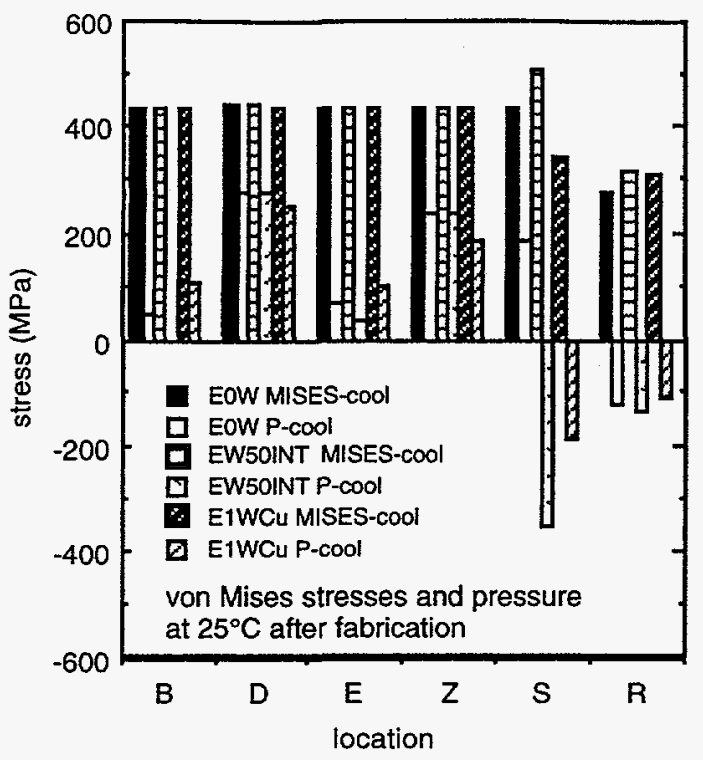

Fig. 10 Pressure and von Mises stresses for post-fabrication stress state at locations indicated in Fig. 6

\section{THERMAL CYCLING}

The case of the $\mathrm{Cu}$ interlayer was modeled through 11 thermal cycles. Near the edge of the joint, the $\mathrm{Cu}$ interlayer had significant plastic strain during the cool down after fabrication, and again with a heat load applied. If significant plastic strain were to continue during thermal cycling, then rapid thermal fatigue would be a concern.

The thermal history included the fabrication step and cooling to $25^{\circ} \mathrm{C}$, and 11 cycles with heat load of $5 \mathrm{MW} / \mathrm{m}^{2}$ (with $160^{\circ}$ $\mathrm{C}$ cooling water) followed by cooling to $25^{\circ} \mathrm{C}$. The kinematic (work) hardening ${ }^{*}$ model was used here.

Fig. 11 shows the stress-strain conditions at the centroid of the second element from the left (second vertical group of points from left in Figs. 2-5, 7, 8; the location is $0.064 \mathrm{~mm}$ from the free edge.) The start of the thermal cycling path is noted in Fig. 11. The path moves downward (arrows) toward lower stresses and strains when the heat load of $5 \mathrm{MW} / \mathrm{m}^{2}$ is applied. The reverse occurs during cooling to $25^{\circ} \mathrm{C}$ at the end of each cycle. When the sample is cool, the stresses and cumulative plastic strains are greatest; these are respectively for $\mathrm{X}$ and $\mathrm{Y}$, about 40 and $75 \mathrm{MPa}$ and $-2.3 \%$ and $0.4 \%$.

\section{OTHER WORK}

In a broader study (not yet reported) from which the results here are taken, beryllium $(\mathrm{Be})$ armor with $\mathrm{Al}$, $\mathrm{AlBeMet}^{\mathrm{TM}}$ or $\mathrm{Cu}$ interlayers was studied. An initial lesson learned was that unacceptably high residual stresses for cases with fabrication at $900^{\circ} \mathrm{C}$, decreased to what are expected to be acceptable values

"Kinematic hardening is used where the Baushinger effect is likely to be important, i.e., deviation from the elastic load curve occurs at stresses below yield under a reverse load. In the simple kinematic hardening procedure in $A B A Q U S$, straining in one direction reduces the yield stress in the opposite direction.

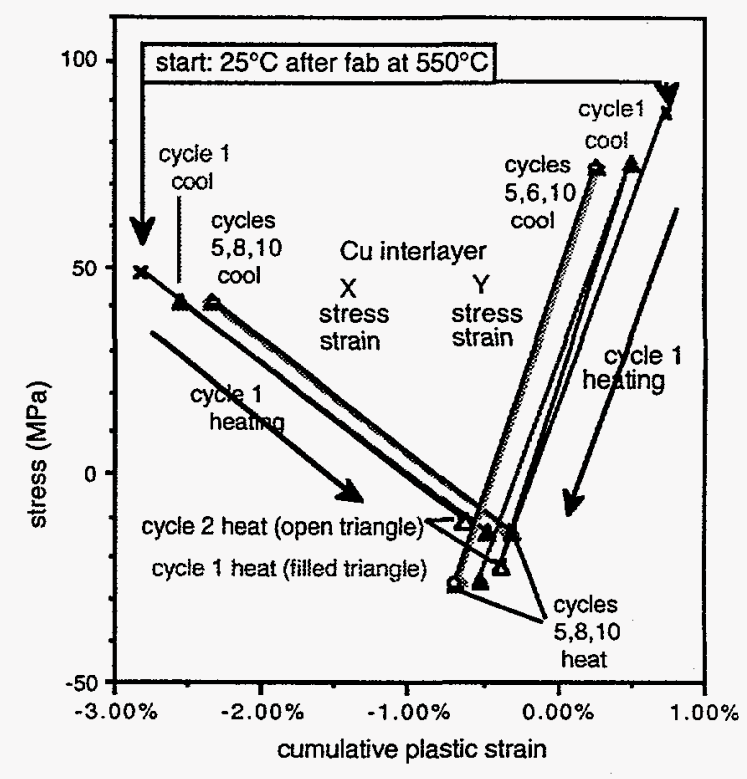

Fig. 11 Stress vs. cumulative plastic strain in the $1 \mathrm{~mm} \mathrm{Cu}$ interlayer for selected thermal cycles

when the fabrication temperature was reduced to $550^{\circ} \mathrm{C}$. For cases with $\mathrm{Be}$ armor, there was some reduction in stresses with interlayers, but the effect was less than for $\mathrm{W}$ armor because the mismatch in thermal expansion between $\mathrm{Be}$ and $\mathrm{CuCrZr}$ is less than that between $\mathrm{W}$ and $\mathrm{CuCrZr}$.

Cases were also run with a symmetry boundary at the right side of the mesh. This simulates the design with dual cooling passages used by the European ITER Team for high heat flux applications in the divertor. (The US ITER Team used a dual passage channel initially but switched to a hypervapotron.)

\section{CONCLUSIONS}

The case with the W50-Cu50 interlayer had the least plastic strain but also the highest stresses at the edge, a known site of concern for the initiation of fatigue cracks. Conversely, the case with the $1 \mathrm{~mm} \mathrm{Cu}$ interlayer had the lowest stresses but the greatest plastic strains, and the analysis indicated continuing cyclic plastic strains during thermal cycling.

With thermal cycling, the cumulative plastic strains change; and both the $\mathrm{X}$ and $\mathrm{Y}$ stress ranges and plastic strain ranges remain fairly constant. The cumulative plastic strain ranges do not go to zero; and thermal fatigue is a likely concern. Testing the robustness of such joints in thermal fatigue tests would seem a prudent step for a design with a $\mathrm{Cu}$ interlayer.

\section{ACKNOWLEDGEMENT}

The author wishes to thank Dr. Bob Watson of Sandia National Laboratories for many helpful discussions on this and other stress analyses. 